
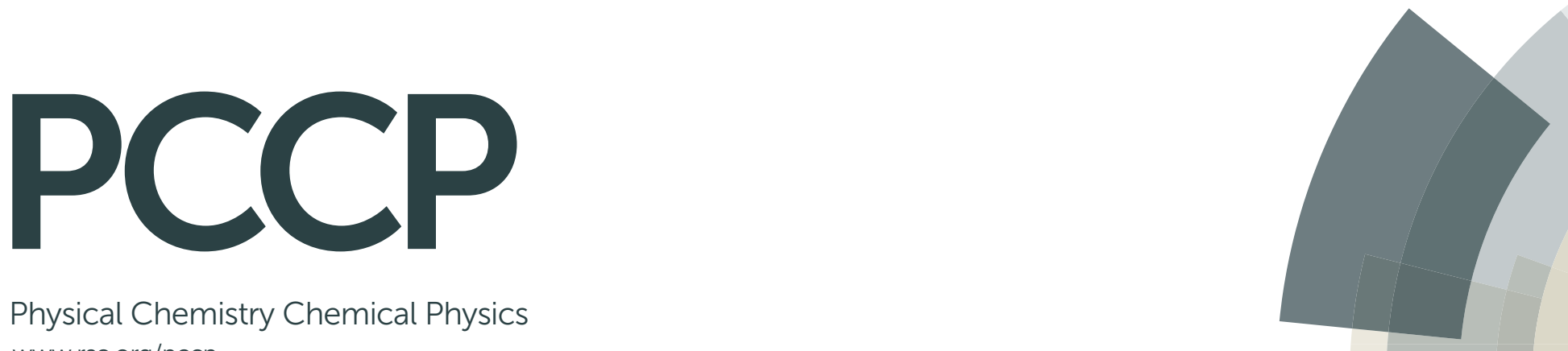

Physical Chemistry Chemical Physics www.rsc.org/pccp

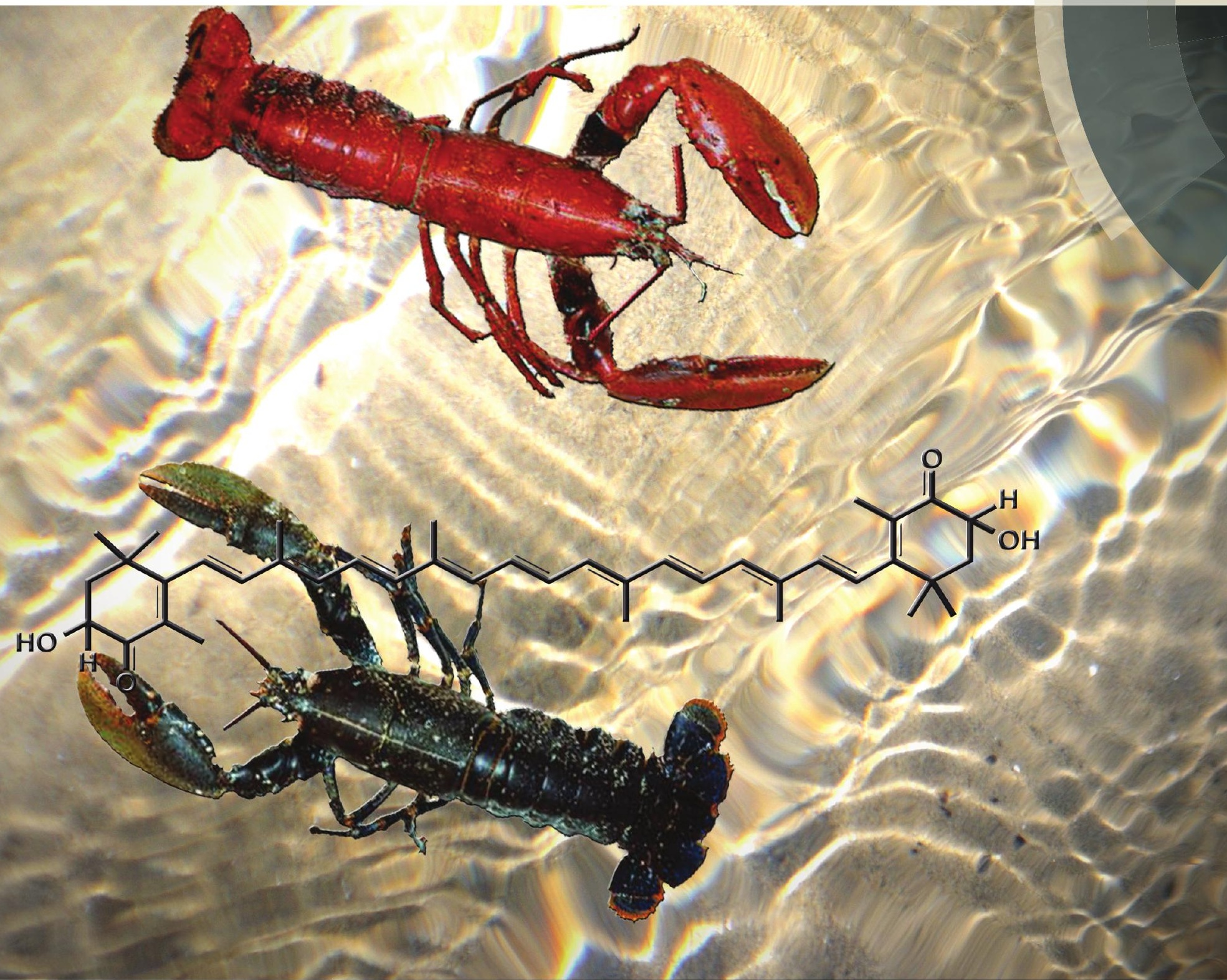

ISSN 1463-9076

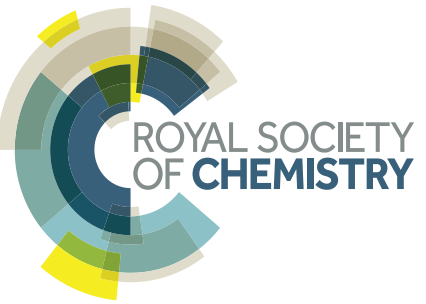




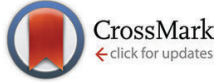

Cite this: Phys. Chem. Chem. Phys., $2015,17,16723$

Received 31st December 2014, Accepted 13th March 2015

DOI: $10.1039 / c 4 c p 06124 a$

www.rsc.org/pccp

\title{
On the origin and variation of colors in lobster carapace $\uparrow$
}

\author{
Shamima Begum, ${ }^{a}$ Michele Cianci, ${ }^{b}$ Bo Durbeej, ${ }^{c}$ Olle Falklöf, ${ }^{c}$ Alfons Hädener, $\ddagger^{a}$ \\ John R. Helliwell, ${ }^{\star a}$ Madeleine Helliwell, ${ }^{a}$ Andrew C. Regan ${ }^{a}$ and C. Ian F. Watt ${ }^{a}$
}

\begin{abstract}
The chemical basis of the blue-black to pink-orange color change on cooking of lobster, due to thermal denaturation of an astaxanthin-protein complex, $\alpha$-crustacyanin, in the lobster carapace, has so far been elusive. Here, we investigate the relaxation of the astaxanthin pigment from its bound enolate form to its neutral hydroxyketone form, as origin of the spectral shift, by analyzing the response of UV-vis spectra of a water-soluble 3-hydroxy-4-oxo- $\beta$-ionone model of astaxanthin to increases in $\mathrm{pH}$, and by performing extensive quantum chemical calculations over a wide range of chemical conditions. The enolization of astaxanthin is consistent with the $\mathrm{X}$-ray diffraction data of $\beta$-crustacyanin (PDB code: 1GKA) whose crystals possess the distinct blue color. We find that enolate formation is possible within the protein environment and associated with a large bathochromic shift, thus offering a cogent explanation for the blue-black color and the response to thermal denaturation and revealing the chemistry of astaxanthin upon complex formation.
\end{abstract}

\section{Introduction}

In the last decade the carotenoid astaxanthin $\left(3,3^{\prime}\right.$-dihydroxy- $\beta$ carotene-4, $4^{\prime}$-dione) has gained interest in the nutraceutical and cosmetic industries due to its antioxidant activity with potential applications against cardiovascular problems, different types of cancer and some diseases of the immunological system. ${ }^{1}$ Very recently, for instance, astaxanthin preparations have reached the mass market as anti-aging skincare products with the commercial name of ASTALIFT (C) FUJIFILM Corporation). The red color displayed by isolated astaxanthin or its preparations, 1 (Scheme 1), often differs from that of the in vivo material, ${ }^{2}$ as represented by the familiar blue-black of the shell of live lobsters which reverts on cooking to the pink-orange color of dilute astaxanthin solutions. The dark color arises from an astaxanthin-protein complex, $\alpha$-crustacyanin, ${ }^{3}$ whose atomic structure, despite recent progress, ${ }^{4,5}$ is as yet unknown. The crystal structure of a blue crystal of a dissociation product, $\beta$-crustacyanin, ${ }^{6}$ prompted renewed interest in the origins of the large bathochromic shift of the UV-vis absorption. ${ }^{7}$ Compared with

\footnotetext{
${ }^{a}$ School of Chemistry, University of Manchester, Manchester, M13 9PL, UK. E-mail: john.helliwell@manchester.ac.uk

${ }^{b}$ EMBL, PETRA III, DESY, Notkestrasse 85, 22603 Hamburg, Germany

${ }^{c}$ Division of Computational Physics, IFM, Linköping University,

SE-58183 Linköping, Sweden

$\dagger$ Electronic supplementary information (ESI) available: Complementary material for compound preparation and characterization and details and results of the quantum chemical calculations. See DOI: 10.1039/c4cp06124a

¥ Pfaffenlohweg 29, CH-4125 Riehen, Switzerland.
}

uncomplexed 1, shifts are 100 and $160 \mathrm{~nm}$ for $\beta$-crustacyanin and $\alpha$-crustacyanin, respectively. ${ }^{6}$

The crystal structure of $\beta$-crustacyanin reveals two protein sub-units linked by a pair of astaxanthin molecules, ${ }^{6}$ modeled therein as $\alpha$-hydroxyketone tautomers 1 . Terminal oxygenated rings are in close association, at one end of each astaxanthin, with the nitrogen of a histidine of one protein and, at the other end, with a water molecule and the acidic phenolic hydroxyl of a tyrosine residue of the second protein. These rings are almost coplanar with the polyene chains, which are slightly bowed with a closest approach of about $7 \AA$.

Two distinct themes have developed in explanation for the coloration. The first, and most thoroughly investigated, focuses on physical arrangements of the astaxanthins in the protein complexes. The angles of twist about the C6-C7 (and $\mathrm{C6}^{\prime}-\mathrm{C7}^{\prime}$ ) bonds of the astaxanthins are much reduced from those found in the 6-s-cis conformation of uncomplexed astaxanthin $\left(\mathrm{ca} .50^{\circ}\right)$, to a 6-s-trans conformation with end rings coplanar with the polyene chains in the protein bound form, permitting enhanced overlap along the conjugated array in the complexed forms. Exciton coupling between the paired astaxanthins in $\beta$-crustacyanin has also been considered. Quantum chemical calculations and experiment, however, suggest that neither conformational change nor exciton coupling can account for more than $30 \%$ of the observed shift, with the larger contribution arising from co-planarization of the end rings. ${ }^{8-10}$ Kuhn and Sörensen suggested in 1938 a second theme, ${ }^{11}$ which remained largely neglected, involving a reversible ionization of the astaxanthins upon complexation. The consequences of deprotonation of an 


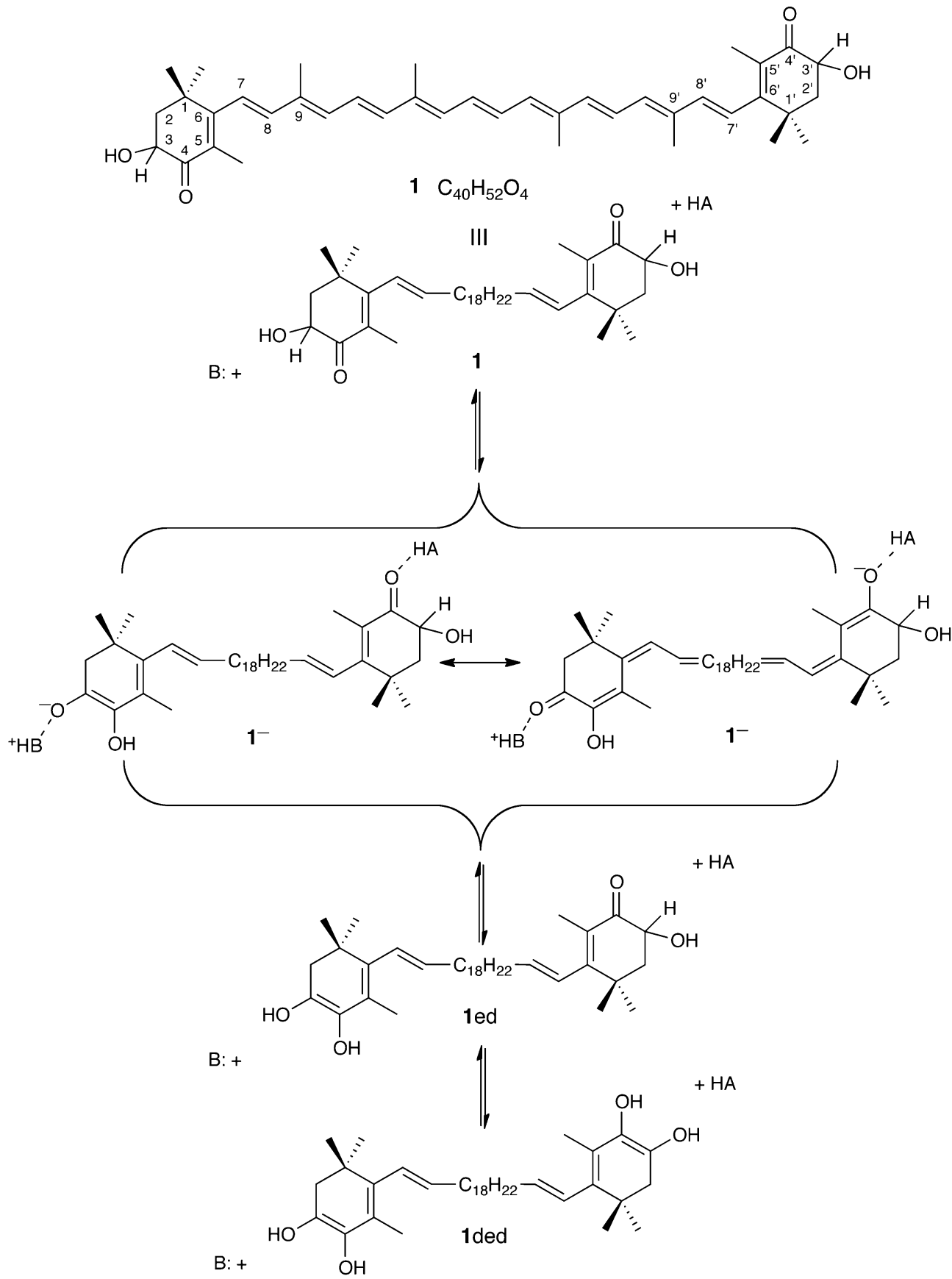

Scheme 1 The structure of astaxanthin (1) and acid-base (HA and B) induced tautomerism of astaxanthin producing the enolate $\mathbf{1}^{-}$and the ene-diol tautomer 1ed. Initial slow deprotonation of 1 at C3 followed by rapid proton transfer from $\mathrm{O} 3$ to $\mathrm{O} 4$ yield the enolate $\mathbf{1}^{-}$capable of extended formal delocalization of the negative charge through the polyene chain to $\mathrm{O}^{\prime}$. Reprotonation at $\mathrm{O} 3$ yields the ene-diol tautomer 1 ed. Further similar chemistry leads to 1 ded.

$\alpha$-hydroxycyclohexenone residue, and subsequent proton transfers, are shown in Scheme 1. However, Buchwald and Jencks ${ }^{12}$ stated that the proteins involved did not contain a site sufficiently basic to retain a proton.

The viability of enolate formation, however, also depends on the acidity of astaxanthin and although this remains unquantified, we note that much simpler compounds, also capable of forming an $\alpha$-hydroxylated enolate in which the negative charge is distributed between two oxygen atoms, including 2,3-dihydroxy-2-propenal (triose reductone) and ascorbic acid, ${ }^{13,14}$ are relatively strong organic acids $\left(\mathrm{p} K_{\mathrm{a}}(1)=5.2\right.$ and 4.1 , respectively) with second ionizations $\left(\mathrm{p} K_{\mathrm{a}}(2) \approx 13\right)$ also accessible in water. A priori rejection of the possibility of enolate formation within the protein thus seems premature. While solutions of astaxanthin in a strongly basic organic medium are known to develop deep blue colors, ${ }^{15}$ quantitative studies in aqueous media require disentangling the effects of aggregation ${ }^{16,17}$ from those of ionization. We have therefore examined the behavior 


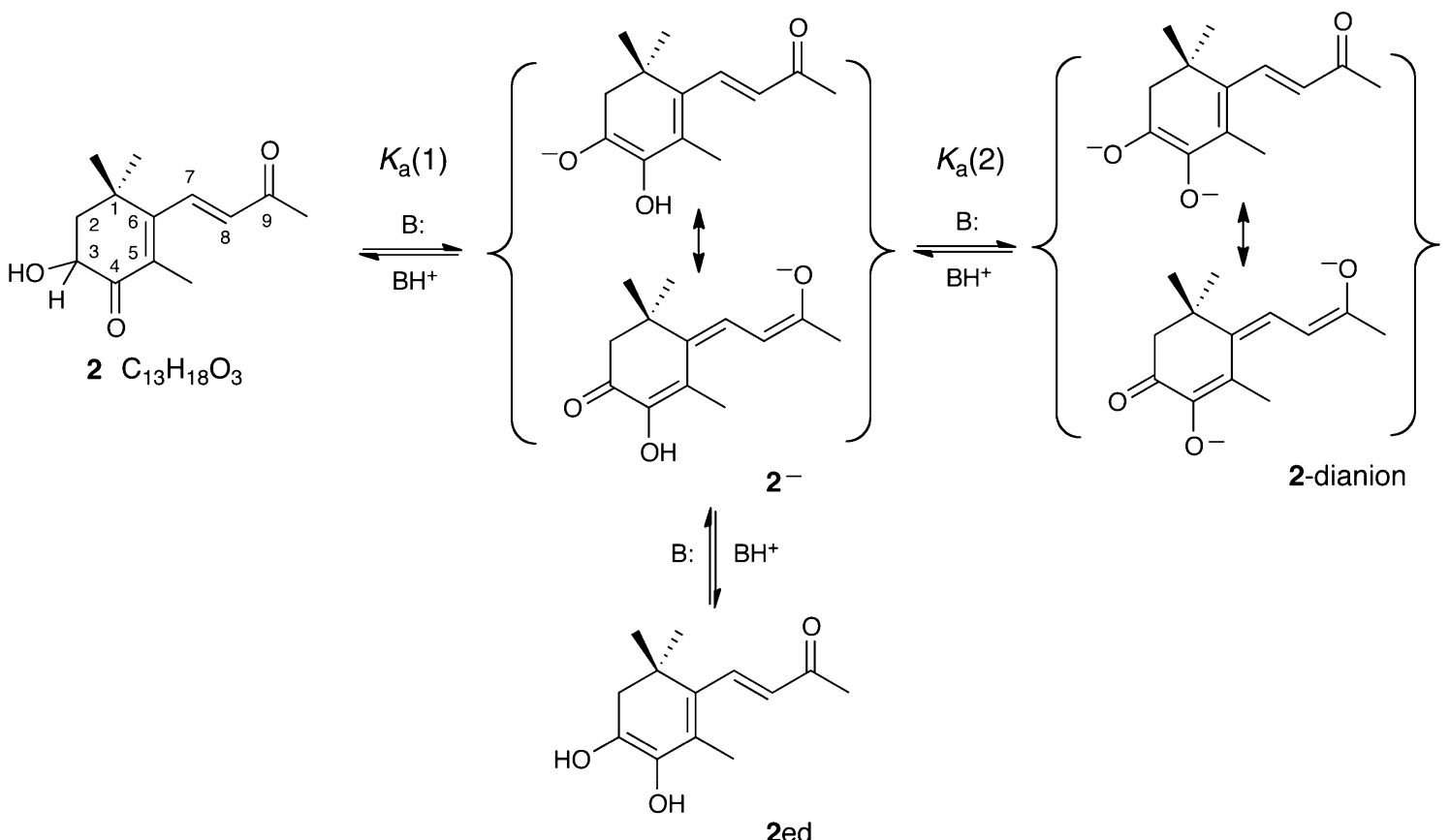

Scheme 2 The structures of 3-hydroxy-4-oxo- $\beta$-ionone (2) and its ene-diol tautomer 2 ed, and their relationships to possible anionic deprotonation products. Deprotonation of $\mathbf{2}$ at $\mathrm{C} 3$ followed by proton transfer from $\mathrm{O} 3$ to $\mathrm{O} 4$ yield the enolate $\mathbf{2}^{-}$, with a sharing of the negative charge by conjugation between $\mathrm{O} 3$ and $\mathrm{O} 9$. Reprotonation at $\mathrm{O} 3$ yields the ene-diol tautomer 2ed. A dianion, 2-dianion, is accessible through deprotonation of the enolic hydroxyl group of $\mathbf{2}^{-}$.

of 3-hydroxy-4-oxo- $\beta$-ionone, $2, \mathrm{C}_{13} \mathrm{H}_{18} \mathrm{O}_{3}$, as a water-soluble model that retains the trimethylated $\alpha$-hydroxycyclohexenone of astaxanthin but replaces the rest of the molecule with a simpler $\alpha-\beta$ unsaturated ketone at the 6-position of the ring. This permits formal conjugation of the ring carbonyl (at $\mathrm{C} 4$ ) with that on the side chain at $\mathrm{C} 9$ through the $\mathrm{C} 6-\mathrm{C} 7$ bond, which occupies the same steric environment as the corresponding bond in astaxanthin. This compound, readily synthesized from $\beta$-ionone, ${ }^{18,19}$ is shown by NMR spectroscopy to exist as its ketonic tautomeric form in both methanol and chloroform solution. Its enolization and enolate chemistry, expected to mimic that of astaxanthin (Scheme 1), is shown in Scheme 2. Our UV-vis experiments on an astaxanthin model compound and quantum chemical calculations support a mechanism by which the colors of crustacyanin protein complexes arise because astaxanthin is bound in its $\mathbf{1}^{-}$form.

\section{Experimental}

\subsection{Preparation of compounds}

3-Hydroxy-4-oxo- $\beta$-ionone (systematically 6-hydroxy-2,4,4-trimethyl-3-[(1E)-3-oxo-1-buten-1-yl]-2-cyclohexen-1-one), 2, was prepared by the published methods from $\beta$-ionone, ${ }^{18,19}$ and obtained as off-white crystals from hexane whose spectroscopic and physical properties were in accord with literature reports. 2,3-Dehydro-3-hydroxy-4-oxo- $\beta$-ionone (systematically 6-hydroxy2,4,4-trimethyl-3-[(1E)-3-oxo-1-buten-1-yl]-2,4-cyclohexadien-1-one), 3 , was prepared by dissolving $2(0.011 \mathrm{~g})$ in dry methanol $(5 \mathrm{ml})$ in a $50 \mathrm{ml}$ wide-neck RB flask. Aqueous $\mathrm{NaOH}$ solution $(20 \mathrm{ml}$ of $0.2 \mathrm{M}$ ) was added to provide an immediate deep orange colored solution, which was shaken vigorously to ensure full aeration. The open flask was then allowed to stand at ambient temperature $\left(21^{\circ} \mathrm{C}\right)$ with periodic vigorous shaking for 24 hours during which time the orange color faded noticeably. Glacial acetic acid was then added by microdropper until the residual color was discharged $(\mathrm{pH}<8)$. The colorless solution was then evaporated to dryness under vacuum maintaining $T<30{ }^{\circ} \mathrm{C}$, the oily residue was taken up in chloroform, and filtered through a cotton wool wad. Examination by TLC (silica, eluting with 50:50 vol/vol ethyl acetate: hexane) showed that the solution contained traces of residual unchanged 2 and a single major, more mobile product, which was isolated by preparative TLC on silica and crystallized from ether-hexane as off-white needles. For details, see the ESI. $\dagger$

\subsection{General methods}

NMR spectra were recorded on Brüker 300,400 or 500 AMX spectrometers. Infrared spectra were recorded on a Perkin-Elmer Spectrum FTIR and were run as liquid films or solids in an ATR attachment. UV-vis investigations were carried out on a Cary-50 BIO spectrometer fitted with a thermostated block set to $30^{\circ} \mathrm{C}$. Mass spectra were recorded on a Hewlett Packard HP5791A MSD. For details, see the ESI. $\dagger$

\subsection{Quantum chemical calculations}

UV-vis spectra and $\mathrm{p} K_{\mathrm{a}}$ values were determined in aqueous and methanol solutions based on primarily density functional theory (DFT) calculations. Bulk solvation effects were accounted for using the CPCM polarizable conductor calculation model. ${ }^{20}$ Geometry optimizations were throughout carried out in a water 
or methanol solvent using the B3LYP hybrid density functional in combination with a Pople style basis set, either 6-31G(d,p) that does not include diffuse functions, or $6-31+G(d, p)$ that includes diffuse functions on second-row atoms. Complementary geometry optimizations were for benchmark purposes also carried out using three alternative density functionals (BP86, BLYP and M06-2X ${ }^{21}$ ), as well as Møller-Plesset second-order perturbation theory (MP2) and the ab initio approximate coupled-cluster singles and doubles method (CC2). ${ }^{22,23}$ Some of these optimizations were done in the gas phase and with the cc-pVDZ basis set. Based on optimized ground-state geometries, absorption maxima were then obtained as vertical excitation energies calculated using time-dependent DFT (TD-DFT). ${ }^{24-26}$ The TD-DFT calculations were performed with seven different density functionals covering a range of exchange-correlation potentials. Some of these functionals - including $\mathrm{M} 06-\mathrm{HF},{ }^{27}$ $\mathrm{LC}-\omega \mathrm{PBE}^{28,29}$ and LC-BLYP ${ }^{30}$ - have partly been designed to offer a better description of excited states than standard functionals. To assess the performance of TD-DFT, complementary excitedstate calculations were also performed with CC2 and complete active space second-order perturbation theory (CASPT2). ${ }^{31}$ While $\mathrm{CC} 2$ is one of the least costly correlated $a b$ initio methods available today, CASPT2 is widely regarded as the gold standard in the field.

The DFT and MP2 calculations were performed with the GAUSSIAN 09 program. $^{32}$ The CC2 and CASPT2 calculations, in turn, were performed with the TURBOMOLE $6.3^{33,34}$ and MOLCAS $7.6^{35}$ programs, respectively. Further details on the quantum chemical calculations are given in the ESI. $\dagger$

\subsection{Crystallographic refinement}

CNS solve V1.3 ${ }^{36}$ was used to refine the $\beta$-crustacyanin structure (PDB code: 1GKA and r1gkasf ${ }^{6}$ ) in its complex with the two astaxanthin molecules in the hydroxyketone form and the enolate form. For details, see the ESI. $\dagger$

\section{Results and discussion}

\subsection{Spectroscopic studies of the behavior of 3-hydroxy-4-oxo- $\beta$-ionone}

The UV-vis spectra of dilute methanolic solutions of 2 exhibit a $\lambda_{\max }$ at $272 \mathrm{~nm}\left(\varepsilon_{\max }=5.1 \times 10^{3} \mathrm{dm}^{3} \mathrm{~mol}^{-1} \mathrm{~cm}^{-1}\right)$, with a lowintensity shoulder extending out to $394 \mathrm{~nm}$. Solutions in pure water show only a small shift $\left(\lambda_{\max }=275 \mathrm{~nm}\right)$, and no change in either extinction coefficient or shape of the absorption peak. When dilute aqueous solutions are prepared by addition of small aliquots $(20 \mu \mathrm{l})$ of more concentrated methanolic solutions to water, the spectra, after the mixing period ( $c a .20$ seconds), are stable and show no changes comparable to those observed by Giovannetti, et al. ${ }^{17}$ for similar aqueous dilutions of astaxanthin. Thus, we conclude that the smaller hydroxyketone 2 does not participate in aggregate formation at the concentrations (ca. $10^{-4} \mathrm{M}$ ) used in these experiments.

Spectra of the aqueous solutions were also unchanged over long periods after acidification with dilute hydrochloric acid. Addition of aqueous $\mathrm{NaOH}$ solution, with cells maintaining a nitrogen atmosphere over the solution, enabled preparation and monitoring of basic solutions of 2 in water containing $0.7 \%$ ( $\mathrm{vol} / \mathrm{vol}$ ) methanol. A typical sequence of spectra, following addition of 2 to a $0.2 \mathrm{M}$ aqueous $\mathrm{NaOH}$ solution, is shown in Fig. 1a.

In Fig. 1a, trace $A$ is the initial spectrum of 2 with $\lambda_{\max }$ at $275 \mathrm{~nm}$. Over about 45 minutes, this spectrum evolves to trace B, by decay of the peak at $275 \mathrm{~nm}$ and development of new maxima at 278, 356 and $454 \mathrm{~nm}$ (the longest-wavelength new maximum thus presents a bathochromic shift of no less than $180 \mathrm{~nm}$ relative to the parent material). The sequence displays a tight isosbestic point at $308 \mathrm{~nm}$, and sections at any of the new maxima show that the absorbance changes are first order, with a rate constant $k_{\text {obs }}=9.7 \times 10^{-4} \mathrm{~s}^{-1}$. Spectra at this stage were stable for at least one hour, with slow decays associated with leakage of atmospheric oxygen into the cell (see further below). At this stage also, acidification of the solution to $\mathrm{pH} 4$ by addition of the calculated amount of acetic acid quickly regenerated, with no detectable intermediate stages, the original spectrum (trace A). Furthermore, chromatography of an extract confirmed the recovery of 2 and showed only minor traces of other materials.

The spectroscopic changes, A $\rightarrow$ B (Fig. 1a), are consistent with the formation of either of the anions $2^{-}$and 2-dianion, or indeed of a rapidly equilibrating mixture thereof. Properly distinguishing between these possibilities led to examining spectra after equilibration in buffered basic solutions over as wide a $\mathrm{pH}$ range as possible. To avoid prolonged equilibration times and reproducibility issues due to slow infusion of atmospheric oxygen into the media, the solutions were equilibrated in 0.2 $\mathrm{M} \mathrm{NaOH}$, (spectrum B in Fig. 1a), and then the spectra were examined after adjustment of $\mathrm{pH}$ in both acidic and basic directions.

The results of increasing the basicity of the medium are shown in Fig. 1b. While the original trace $\mathrm{A}$ is included for comparison, the starting point for the chemistry here is trace $\mathrm{B}$, corresponding to equilibrated $2^{-}$and 2-dianion species in a $0.2 \mathrm{M} \mathrm{NaOH}$ solution at $\mathrm{pH}$ 13.2. Traces $\mathrm{C}$ and $\mathrm{D}$ arose from sequential additions of highly concentrated $\mathrm{NaOH}$, increasing the basicity firstly to $\mathrm{pH} 13.3$ and then to $\mathrm{pH}$ 13.7. In both cases, spectra were corrected for small volume changes associated with the additions. In these spectra, the peaks at 278 and $454 \mathrm{~nm}$ increase with increasing basicity, whereas the peak at $356 \mathrm{~nm}$ decreases, with a new isosbestic point appearing at $395 \mathrm{~nm}$. These changes are consistent with a situation in which, in trace $\mathrm{B}$, the peak at $356 \mathrm{~nm}$ is associated with $2^{-}$and the peaks at 278 and $454 \mathrm{~nm}$ with the 2-dianion species. In a further experiment, 2 was equilibrated directly with $2 \mathrm{M} \mathrm{NaOH}$ (pH 14.5), which produced a spectrum that after scaling to match the $395 \mathrm{~nm}$ isosbestic point is shown as trace $\mathrm{E}$ in Fig. 1b. Despite the large variations in ionic strength, trace E falls into the pattern shown by traces B, C and D. A near superimposable trace was again produced when $1.5 \mathrm{M}$ $\mathrm{NaOH}$ was used, indicating that at $\mathrm{pH} 14.5,2$ is almost fully converted to its 2-dianion form.

The results of decreasing the basicity of the medium are shown in Fig. 1c. Again, the starting point is the equilibrated state of $2^{-}$and 2-dianion species (trace B). Addition of measured 


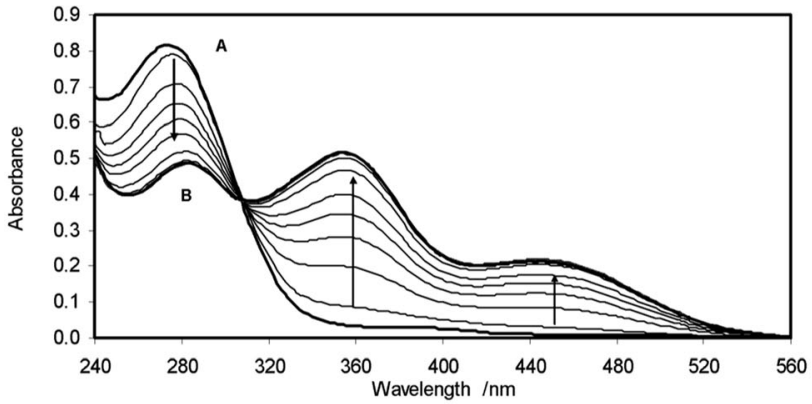

(a)

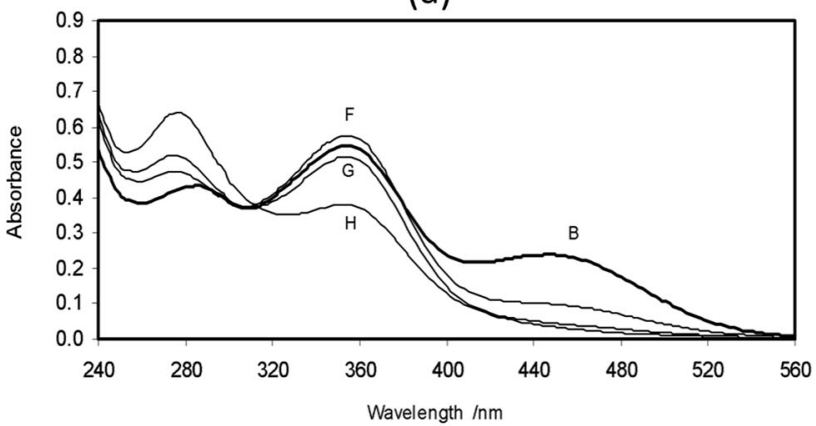

(c)

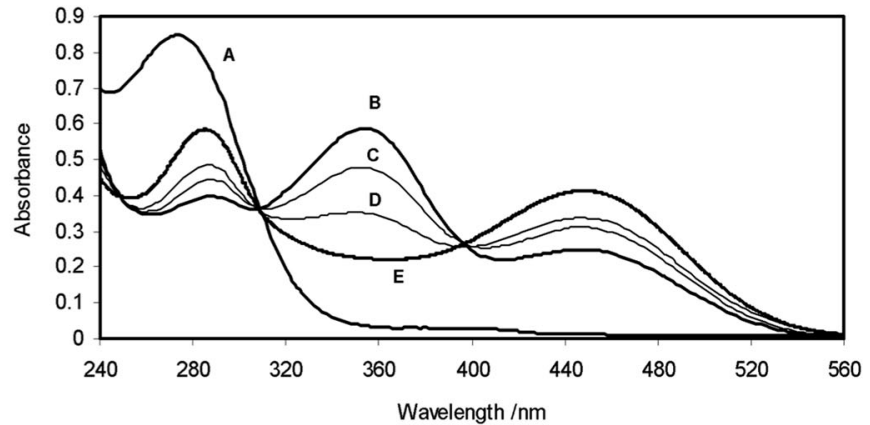

(b)

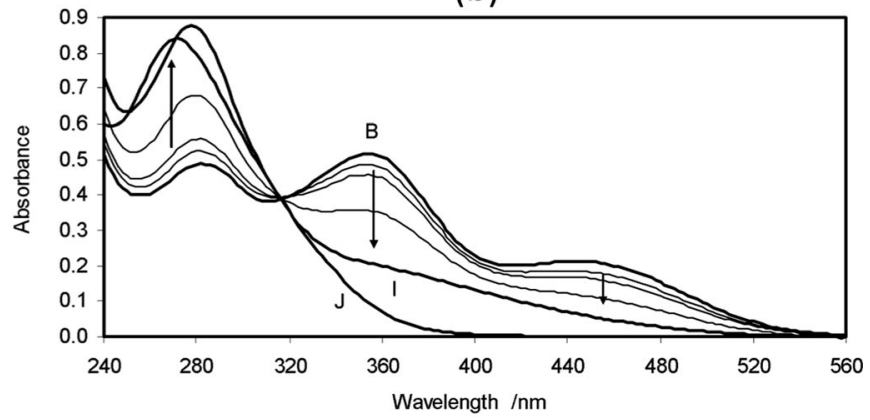

(d)

Fig. 1 Solution spectra of 3-hydroxy-4-oxo- $\beta$-ionone (2): (a) evolution of UV-vis spectra on addition of 2 to a deoxygenated $0.2 \mathrm{M}$ aqueous $\mathrm{NaOH}$ solution at $30{ }^{\circ} \mathrm{C}$. Trace $\mathrm{A}$ is the initial spectrum of 2 with $\lambda_{\max }$ at $275 \mathrm{~nm}$. Over about 45 minutes, this spectrum equilibrates to trace $\mathrm{B}$; (b) comparison of UV-vis spectra at $30{ }^{\circ} \mathrm{C}$ of 2 non-equilibrated (trace A) and equilibrated (trace $\mathrm{B}=\mathrm{pH}$ 13.2) in $0.2 \mathrm{M}$ aqueous $\mathrm{NaOH}$ with those in more concentrated $\mathrm{NaOH}$ solutions (trace $\mathrm{C}=\mathrm{pH} 13.3$, trace $\mathrm{D}=\mathrm{pH}$ 13.7, trace $\mathrm{E}=\mathrm{pH} 14.5$ ); (c) comparison of UV-vis spectra at $30{ }^{\circ} \mathrm{C}$ of 2 equilibrated in $0.2 \mathrm{M}$ aqueous $\mathrm{NaOH}$ (trace $\mathrm{B}=\mathrm{pH}$ 13.2) with those arising when solutions are acidified (trace $\mathrm{F}=\mathrm{pH} 12.6$, trace $\mathrm{G}=\mathrm{pH} 12.1$, trace $\mathrm{H}=\mathrm{pH} 10.4$ ); (d) evolution of $U$-vis spectra at $30{ }^{\circ} \mathrm{C}$ of 2 equilibrated in $0.2 \mathrm{M}$ aqueous $\mathrm{NaOH}$ (trace $\mathrm{B}=\mathrm{pH}$ 13.2) following opening of the cell to air (after 65 minutes, trace I), followed by acidification $(\mathrm{pH} 4$, trace $\mathrm{J})$.

amounts of neat trifluoroethanol, $\mathrm{p} K_{\mathrm{a}}=12.4,{ }^{37}$ then provided solutions with some buffering at $\mathrm{pH}>12$. In trace $\mathrm{F}(\mathrm{pH}=12.6)$, the original peak at $454 \mathrm{~nm}$ associated with 2-dianion decreased substantially, while the original peak at $356 \mathrm{~nm}$ associated with $2^{-}$ increased slightly. Trace $\mathrm{G}(\mathrm{pH}=12.1)$ shows some small depletion of $\mathbf{2}^{-}$and almost complete loss of the 2-dianion. For a more acidic medium yet, a portion of solid sodium bicarbonate, calculated to produce a solution buffered at $\mathrm{pH} 10.4$, was added to a freshly equilibrated solution of 2 in $0.2 \mathrm{M}$ aqueous $\mathrm{NaOH}$. After small scaling of the spectrum to match the isosbestic point, this yielded trace $\mathrm{H}$, in which it is clear that the $356 \mathrm{~nm}$ peak has dropped to about half its original value and there has been substantial growth of the $272 \mathrm{~nm}$ peak associated with 2 itself. Further acidifications continue the trend of reversion to the spectrum of 2.

The spectra and responses to $\mathrm{pH}$ changes presented in Fig. 1a-c are fully consistent with the scheme of deprotonations and proton transfers shown above in Scheme 2, where: (i) deprotonation of 2 at $\mathrm{C} 3$ followed by proton transfer from $\mathrm{O} 3$ to $\mathrm{O} 4$ yield $2^{-}$, with a sharing of the negative charge by conjugation between $\mathrm{O} 3$ and $\mathrm{O} 9$; (ii) reprotonation at $\mathrm{O} 3$ yields the ene-diol tautomer 2ed; and (iii) deprotonation of the enolic hydroxyl group of $2^{-}$produces 2-dianion. The spectra also permit initial estimates of the dissociation constants $K_{\mathrm{a}}(1)$ and $K_{\mathrm{a}}(2)$ defined in Scheme 2. From Fig. 1c, a comparison of traces $\mathrm{H}$ and F suggests that at $\mathrm{pH} 10.4$, there is a $c a$. $50 \%$ conversion of 2 to $2^{-}$, with little further conversion to the 2-dianion. In that case, application of the Henderson-Hasselbach equation to the equal concentrations of 2 and $2^{-}$gives $\mathrm{p} K_{\mathrm{a}}(1) \approx 10.4$. Similar inspection of Fig. 1b, comparing traces B and E, suggests that at $\mathrm{pH}$ 13.2, the equilibrated solution contains near equal amounts of $2^{-}$and 2-dianion, with little residual un-ionized 2, so that $\mathrm{p} K_{\mathrm{a}}(2) \approx 13.2$. These values of the dissociation constants might be compared with the corresponding values of $4.12\left(\mathrm{p} K_{\mathrm{a}}(1)\right)$ and $11.51\left(\mathrm{p} K_{\mathrm{a}}(2)\right)$ for ascorbic acid. ${ }^{38}$

The preceding analysis providing estimates of $K_{\mathrm{a}}(1)$ and $K_{\mathrm{a}}(2)$ does not take into account the possibility that 2 can also be ionized to form its alkoxide, by deprotonation of the secondary alcohol (Scheme 3a), a process expected to have little effect on the UV-vis spectrum of 2 . However, since this process involves equilibration of an oxygen acid, the associated relaxation in either acid or base in aqueous medium should be fast ${ }^{39}$ compared to that for the deprotonation leading to $2^{-}$, irrespective of thermodynamic acidities. The value of 10.4 for $\mathrm{p} K_{\mathrm{a}}(1)$ extracted above is not then simply that for dissociation of $\mathbf{2}$ as a carbon acid. Rather, any appreciable alkoxide formation would call for a correction according to the equation included in Scheme 3a, whereby the apparent ionization constant will be an underestimate of the true value, i.e., $\mathrm{p} K_{\mathrm{a}}(\mathrm{C} 3-\mathrm{H})<\mathrm{p} K_{\mathrm{a}}(1)$.

For simple secondary aliphatic alcohols $\left(16<\mathrm{p} K_{\mathrm{a}}(\mathrm{O} 3-\mathrm{H})<\right.$ 16.5), extents of alkoxide formation would be small, even in 


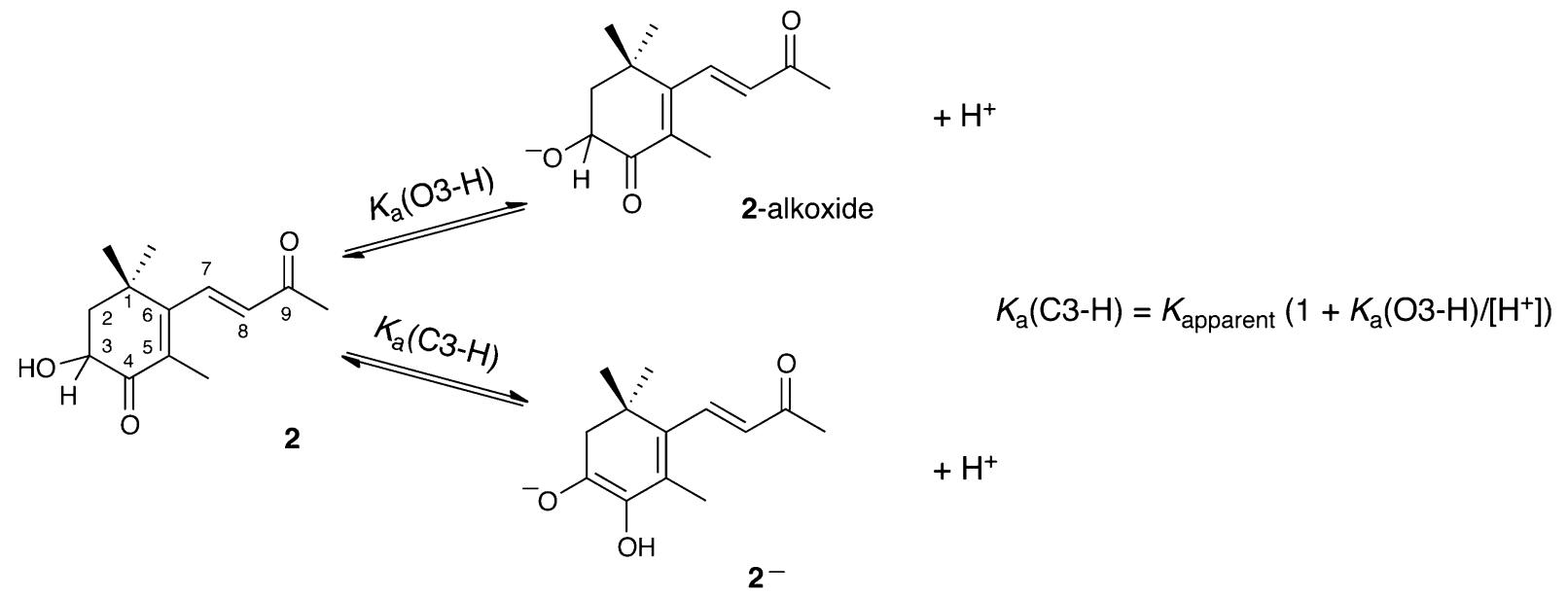<smiles>CC(=O)C=C[C@@]1(C)CC(O)(O)C(=O)C(C)=C1C=C(C)C</smiles>

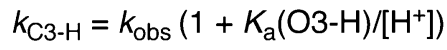

(b)<smiles>CC(=O)/C=C/C1=C(C)C(=O)[C@](O)(/C=C/[C@@H](C)O)CC1(C)C</smiles>

(c)

Scheme 3 Equilibria of 3-hydroxy-4-oxo- $\beta$-ionone (2): (a) competing O- and C-dissociations; (b) the effect of fast equilibration with alkoxide on the observed rate constant for enolate formation; (c) the action of oxygen on basic solutions.

strongly basic aqueous solutions, and the discrepancy between apparent and actual carbon acid dissociation constants would be undetectably small. The secondary alcohol in 2 , however, is in a polar environment, and empirical additivity relationships (based on a very sparse data set) have yielded a relationship ${ }^{40}$ between acidity and Taft's polar substituent parameters $\left(\sigma^{*}\right)$ which, using $\sigma^{*}=2.0$ for $-\mathrm{COCH}=\mathrm{CH}_{2},{ }^{41}$ gives $\mathrm{p} K_{\mathrm{a}}(\mathrm{O} 3-\mathrm{H}) \approx 13.1$ for 2 . Even with this value, the difference between apparent and actual carbon acid dissociation constants would be small.

However, the uncertainty in the estimate of $\mathrm{p} K_{\mathrm{a}}(\mathrm{O} 3-\mathrm{H})$ is large, but while we have no direct experimental measurement, the kinetics of formation of $2^{-}$indicates that the value may be much higher than 13.1. This is also found by the quantum chemical calculations further described below. Earlier, we noted that the formation of $2^{-}$and 2-dianion mixture in $0.2 \mathrm{M}$ $\mathrm{NaOH}$ show first-order behavior with $k_{\mathrm{obs}}=9.7 \times 10^{-4} \mathrm{~s}^{-1}$.
Assuming that the reaction is also first order in hydroxide, the second-order rate constant for the reaction is then $4.9 \times$ $10^{-3} \mathrm{M}^{-1} \mathrm{~s}^{-1}$. Comparison with the second-order rate constants for deprotonation (by hydroxide) at $25{ }^{\circ} \mathrm{C}$ of more familiar carbon acids such as nitromethane $\left(\mathrm{p} K_{\mathrm{a}}=10.2\right)$ and acetylacetone $\left(\mathrm{p} K_{\mathrm{a}}=8.9\right)$ of $2.76 \times 10 \mathrm{M}^{-1} \mathrm{~s}^{-1}$ (ref. 42$)$ and $3.98 \times$ $10^{4} \mathrm{M}^{-1} \mathrm{~S}^{-1},{ }^{43}$ respectively, makes it very clear that carbon deprotonation of 2 is $>10^{3}$ slower than for a carbon acid of similar acidity. Nothing obvious in the structure of 2 accounts for the low reactivity, but if, under the conditions, 2 existed largely as its alkoxide and did not rearrange or react with hydroxide to yield $2^{-}$, the rate constant found here would need to be scaled upwards as shown in Scheme $3 \mathrm{~b}$ to yield a true value, $k_{\mathrm{C} 3-\mathrm{H}}$, for the second-order rate constant for carbon deprotonation of 2 by hydroxide. If the correction factor $k_{\mathrm{C} 3-\mathrm{H}} / k_{\mathrm{obs}}$ is indeed $c a .10^{3}$, it is possible to work out an estimate of 10.0 for 
the true $\mathrm{p} K_{\mathrm{a}}(\mathrm{C} 3-\mathrm{H})$ value of $2(c f$. with the above estimate of 10.4 for the $\mathrm{p} K_{\mathrm{a}}(1)$ value of 2$)$.

\subsection{The oxidation chemistry}

As noted earlier, the basic solutions of 2 are extremely sensitive to oxygen. In view of possible parallels with the reported reactions of astaxanthin with oxygen in basic medium, ${ }^{44}$ we have examined this behavior (Fig. 1d). Trace B evolves, after opening to air following zero-order kinetics over 65 minutes, to yield spectrum I. Further changes then become extremely slow with spectrum I persisting indefinitely if the cell is again closed. Qualitatively, zero-order rates are proportional to hydroxide concentration so that 2-dianion is implicated as the reactive species. After acidification to $\mathrm{pH} 4$, there is an immediate change to yield spectrum $\mathrm{J}$.

To identify the oxidation products, a large-scale reaction was carried out. Chromatography showed formation of a single new product. After acidification of the solution, a crystalline product was isolated, molecular formula $\mathrm{C}_{13} \mathrm{H}_{16} \mathrm{O}_{3}$, thus a simple oxidation product of 2 . Revealingly, proton NMR spectroscopy confirmed loss of the ABX signal, associated with the C2 and C3 hydrogens of 2 and its replacement by a single one-proton signal at $\delta$ 6.04. Geminal methyl groups now show a single signal indicating equivalent environments. The spectrum also shows a broad $1 \mathrm{H}$ signal at $\delta 6.28$, assigned to a hydrogen bonded $\mathrm{OH}$, whose presence was confirmed by IR spectroscopy. The analytical data are consistent with this oxidation product being the enol 2,3 -dehydro-3-hydroxy-4-oxo- $\beta$-ionone ( 3 in Scheme $3 \mathrm{c}$ ), bearing the same relationship to 2 as astacene bears to astaxanthin (with which it often co-occurs ${ }^{1}$ ). The UV-vis spectra of 3 in neutral and basic aqueous solution were superimposable on traces J and I in Fig. 1d. Responses of spectra to changes in $\mathrm{pH}$ were immediate, and the behavior in borate buffers gave $\mathrm{p} K_{\mathrm{a}}=9.9$. The chemistry is summarized in Scheme $3 \mathrm{c}$ in which we suggest that atmospheric oxygen reacts with 2-dianion, yielding the enolate of 3 and probably hydrogen peroxide, as its anion.

\subsection{Quantum chemical calculations on the model system}

Since similar aqueous solution experiments with astaxanthin itself are not possible, due to aggregate formation and the low solubility of astaxanthin in water, we have performed complementary TD-DFT calculations with seven different density functionals, first establishing the ability of these to accurately reproduce the UV-vis spectroscopic behavior of our model compound 2 (see Table S1 of the ESI $\dagger$ ). Notably, the methods to be used for the full astaxanthin system below (M06-HF, LC- $\omega$ PBE and LC-BLYP) reproduce the experimental $\lambda_{\max }$ of 2 with an accuracy of $\sim 10 \mathrm{~nm}(\sim 0.15 \mathrm{eV})$ for the hydroxyketone and di-anion forms ( 2 and 2-dianion, Scheme 2), and are in qualitative accord with all the experimental UV-vis spectra in that they predict a substantial red shift in the absorption upon formation of the mono-anion from the parent hydroxyketone. Notice, however, that the calculations give larger shifts than that observed experimentally.

In light of this discrepancy, we have quite exhaustively investigated whether factors that may have a negative impact on the accuracy of TD-DFT excitation energies are at play. This investigation, which is fully described in Sections 4.1-4.5 of the $\mathrm{ESI}^{\dagger}+$ and presented in Tables $\mathrm{S} 1$ and S3-S9, includes a comparison of TD-DFT results with CC2 and CASPT2 ab initio results, an assessment of how molecular geometries and choice of basis set influence the calculated $\lambda_{\max }$, and additional benchmark calculations on the oxidation product of 2 (2,3-dehydro-3-hydroxy-4-oxo- $\beta$ ionone) and on 2,3-dihydroxy-2-propenal, which contains the minimum carbon framework in which conjugation between a carbonyl group and an ene-diol may occur. Overall, this investigation shows that TD-DFT calculations constitute a reliable tool for obtaining a qualitatively accurate assessment of how acid-base chemistry influences the UV-vis spectroscopic behavior of astaxanthin and models thereof, and strongly indicates that more elaborate $a b$ initio calculations would support the same conclusions.

Describing the solvent using a hybrid cluster-continuum approach, ${ }^{45}$ we also calculated the $\mathrm{p} K_{\mathrm{a}}$ dissociation constants of 2 (Table S2, ESI $\dagger$ ). Since most of these p $K_{\mathrm{a}}$ values are available from experiment, the calculations serve both as a test of the experimental predictions and a validation of the computational accuracy of DFT for the present systems, with implications also for the excited-state calculations discussed below.

Firstly, it can be seen that the experimentally measured $\mathrm{p} K_{\mathrm{a}}$ of 10.4 for deprotonation of the hydroxyketone at $\mathrm{C} 3\left(\mathrm{p} K_{\mathrm{a}}(\mathrm{C} 3-\mathrm{H})\right.$ in Table S2 (ESI $\dagger$ ) and Scheme $3 ; \mathrm{p} K_{\mathrm{a}}(1)$ Scheme 2) to form the monoanion is reproduced very well, and that the calculated estimates (ranging between 7.7 and 10.6) are not particularly sensitive to the number of explicit water molecules included in the modeling. Given that we propose a mechanism for the bathochromic shift in crustacyanin based on formation of the mono-anion of astaxanthin, it is also notable that this $\mathrm{p} K_{\mathrm{a}}$ is fairly small. From calculations on the ketone form lacking the C3 hydroxyl group (4-oxo- $\beta$-ionone), it is predicted that the smallness of $\mathrm{p} K_{\mathrm{a}}(\mathrm{C} 3-\mathrm{H})$ for the hydroxyketone is due precisely to the $\mathrm{C} 3$ hydroxyl group, because without this group, the calculated $\mathrm{p} K_{\mathrm{a}}(\mathrm{C} 3-\mathrm{H})$ values amount to $\sim 20$ or even higher.

The calculations further predict that $\mathrm{p} K_{\mathrm{a}}(\mathrm{C} 3-\mathrm{H})$ for the hydroxyketone is considerably smaller than the $\mathrm{p} K_{\mathrm{a}}$ for deprotonation of the C3 hydroxyl group to form the alkoxide of the hydroxyketone $\left(\mathrm{p} K_{\mathrm{a}}(\mathrm{O} 3-\mathrm{H})\right.$ in Table $\left.\mathrm{S} 2, \mathrm{ESI} \dagger\right)$. Thus, alkoxide formation should not impact on mono-anion formation. Although the estimates of $\mathrm{p} K_{\mathrm{a}}(\mathrm{O} 3-\mathrm{H})$ vary somewhat with the number of water molecules, the difference between $\mathrm{p} K_{\mathrm{a}}(\mathrm{O} 3-\mathrm{H})$ and $\mathrm{p} K_{\mathrm{a}}(\mathrm{C} 3-\mathrm{H})$ appears to converge to a value of around 10 in the calculations.

In addition to $\mathrm{p} K_{\mathrm{a}}$ values of the hydroxyketone, we have also calculated the $\mathrm{p} K_{\mathrm{a}}$ for deprotonation of the $\mathrm{C} 4$ hydroxyl group of the mono-anion $\left(\mathrm{p} K_{\mathrm{a}}(\mathrm{O} 4-\mathrm{H})\right.$ in Table $\mathrm{S} 2(\mathrm{ESI} \dagger) ; \mathrm{p} K_{\mathrm{a}}(2)$ in Scheme 2) to form the di-anion. This $\mathrm{p} K_{\mathrm{a}}$ has also been determined experimentally, and pleasingly, the calculated values approach $(23.6 \rightarrow 17.9 \rightarrow 14.5)$ the experimental estimate $(13.2)$ to within close to $1 \mathrm{p} K_{\mathrm{a}}$ unit as the number of water molecules is increased.

\subsection{Quantum chemical calculations on different forms of astaxanthin}

The UV-vis $\lambda_{\max }$ of the parent keto form of astaxanthin (1, Scheme 1) was calculated using TD-DFT, ${ }^{24-26}$ employing three different density functionals and two different basis sets. 
Table 1 Calculated $\lambda_{\max }$ (in $\mathrm{nm}$ ), excitation energies $\left(\Delta E\right.$, in $\mathrm{eV}$ ) and oscillator strengths (f) of different forms of astaxanthin ${ }^{a}$

\begin{tabular}{|c|c|c|c|c|c|c|}
\hline Method/basis set ${ }^{b}$ & Solvent & Keto & Mono-enol & Di-enol & Mono-anion & Di-anion \\
\hline LC- $\omega \mathrm{PBE} / \mathrm{I}, \quad \lambda_{\max }(\Delta E, f)$ & $\mathrm{H}_{2} \mathrm{O}$ & $473(2.62,4.53)$ & $482(2.57,4.64)$ & $477(2.60,4.73)$ & $658(1.88,4.43)$ & $779(1.59,5.16)$ \\
\hline LC-BLYP/I, $\quad \lambda_{\max }(\Delta E, f)$ & $\mathrm{H}_{2} \mathrm{O}$ & $463(2.68,4.59)$ & $470(2.64,4.70)$ & $465(2.66,4.79)$ & $643(1.93,4.45)$ & $754(1.64,5.19)$ \\
\hline $\mathrm{LC}-\omega \mathrm{PBE} / \mathrm{II},{ }^{c} \lambda_{\max }(\Delta E, f)$ & $\mathrm{H}_{2} \mathrm{O}$ & $482(2.57,4.47)$ & $490(2.53,4.55)$ & $484(2.56,4.64)$ & $665(1.86,4.45)$ & $796(1.56,4.99)$ \\
\hline LC-BLYP/II,$^{c} \lambda_{\max }(\Delta E, f)$ & $\mathrm{H}_{2} \mathrm{O}$ & $474(2.62,4.52)$ & $481(2.58,4.61)$ & $475(2.61,4.69)$ & $651(1.90,4.50)$ & $774(1.60,5.02)$ \\
\hline M06-HF/I, $\quad \lambda_{\max }(\Delta E, f)$ & $\mathrm{MeOH}$ & $456(2.72,4.39)$ & $463(2.68,4.48)$ & $459(2.70,4.56)$ & $668(1.86,4.05)$ & $791(1.57,4.84)$ \\
\hline Experiment $^{d} \lambda_{\max }\left(\Delta E, \varepsilon_{\max }{ }^{e}\right)$ & Mixture & $476(2.61,10000)$ & - & - & - & - \\
\hline
\end{tabular}

${ }^{a}$ All calculations based on geometries optimized using B3LYP/6-31G(d,p) in combination with a CPCM description of the water or methanol solvent. ${ }^{b}$ Basis set $\mathrm{I}=6-31 \mathrm{G}(\mathrm{d}, \mathrm{p})$; basis set $\mathrm{II}=$ aug-cc-pVDZ. ${ }^{c}$ Solvent effects obtained using the cc-pVDZ basis set and added to gas-phase data obtained with the target aug-cc-pVDZ basis set. ${ }^{d}$ Experimental value in a water-methanol mixture. ${ }^{e} \varepsilon_{\max }$ given in units of $\mathrm{dm}^{3} \mathrm{~mol}^{-1} \mathrm{~cm}^{-1}$.

These results were then compared with the corresponding results obtained for the mono-enol, di-enol, mono-anion and di-anion forms (1ed, $\mathbf{1} \mathrm{ded}, \mathbf{1}^{-}$, and $\mathbf{1}$-dianion, Scheme 1 ). In a preceding step discussed in more detail in Section 4.1 of ESI, $\dagger$ the choice of density functionals for these calculations was established from analogous calculations on the 3-hydroxy-4oxo- $\beta$-ionone model system (2, Scheme 2$)$ and its enolic and anionic forms (2ed, $\mathbf{2}^{-}$, and 2-dianion, Scheme 2).

Starting with the keto form of astaxanthin, it can be seen from Table 1 that all three density functionals (M06-HF, LC- $\omega$ PBE and LC-BLYP) give, in the absence of effects linked to aggregation phenomena, very similar $\lambda_{\max }$ for the water and methanol solvents, and that the experimental value $(476 \mathrm{~nm})$ pertaining to a water-methanol mixture is reproduced with $\sim 20 \mathrm{~nm}$ $(\sim 0.1 \mathrm{eV})$ accuracy. It can also be seen that the relatively small 6-31G(d,p) basis set gives similar $\lambda_{\max }$ as the larger aug-cc-pVDZ basis set, which reflects the pronounced valence character of the strongly absorbing " $\mathrm{B}_{\mathrm{u}}$-like" excited state. Indeed, the diffuse functions included in the aug-cc-pVDZ basis set red shifts the $\lambda_{\max }$ by no more than $13 \mathrm{~nm}(0.07 \mathrm{eV})$.

Turning to the calculations on the other forms of astaxanthin also summarized in Table 1, but for which experimental data are not available, we first observe that neither single nor double enolization is predicted to significantly shift the $\lambda_{\max }$ of the parent keto form, excluding tautomerism alone in the protein-bound astaxanthins as the origin of the much larger observed bathochromic shift. Notably, however, the calculations show that deprotonation of $\mathrm{C} 3$ followed by proton transfer between the oxygen atoms attached to $\mathrm{C} 3$ and $\mathrm{C} 4$ (or, equivalently, single enolization followed by deprotonation of the C3 hydroxyl group) to form the mono-anion, $\mathbf{1}^{-}$, is associated with a red shift, lying uniformly between 177 and $212 \mathrm{~nm}(0.71-0.86 \mathrm{eV})$ for all methods, thus larger than the bathochromic shift in $\beta$-crustacyanin $\left(\lambda_{\max }\right.$ at $570 \mathrm{~nm})$ and consistent with that in $\alpha$-crustacyanin $\left(\lambda_{\max }\right.$ at $630 \mathrm{~nm}$ ). For the dianion (1-dianion), the calculations yield a bathochromic shift of the order of $300 \mathrm{~nm}$, bringing the absorption into the near-infrared $\left(\lambda_{\max } \approx 750-800 \mathrm{~nm}\right)$.

\subsection{Crystallographic refinement}

Re-examination of the crystal structure of $\beta$-crustacyanin ${ }^{6}$ indeed confirms that enolate $\left(\mathbf{1}^{-}\right)$and enolic (1ed) forms are as compatible with the crystal structure as the hydroxyketone form 1. Bond angles and bond distances for the end rings and polyene chain were derived from the published models of astaxanthin, thus maintaining the 6-s-trans conformation around the $\mathrm{C} 6-\mathrm{C} 7$ and $\mathrm{C6}^{\prime}-\mathrm{C7}^{\prime}$ bonds ${ }^{46,47}$ (see also the $\mathrm{ESI} \dagger$ ).

\section{Conclusions}

The experiments and calculations that we have presented show that our model system 2 behaves kinetically and thermodynamically as a pseudo-acidic indicator, ${ }^{39}$ with slow carbon deprotonation yielding an extended enolate stable enough to exist in water at $\mathrm{pH} \approx 10$. The ability of the computational methods to reproduce experimental observations for the model system validates their application to astaxanthin itself, $\mathbf{1}$, its tautomers $\mathbf{1 e d}$ and $\mathbf{1 d e d ,}$ and the enolate $\mathbf{1}^{-}$, thus confirming that enolate formation is associated with a $177-212 \mathrm{~nm}(0.71-0.86 \mathrm{eV})$ bathochromic shift. Since the conjugation in astaxanthin is much more extensive than in the model compound we have studied, its colored enolate should be even more stable and accessible at lower $\mathrm{pH}$. Additionally, deprotonation within the protein would yield the extended enolate bound in a pre-organized site, retained by hydrogen bonding between $\mathrm{O} 3$ and the histidine at one end, and between $\mathrm{O} 4$ ' and the water-tyrosine pair at the other (i.e., in Scheme 1, B $=$ His and $\mathrm{HA}=\mathrm{HOH}+\mathrm{Tyr})$. The blue-black to pink-orange color change on cooking of lobster would then be explained by thermal denaturation of $\alpha$-crustacyanin releasing the astaxanthin from its bound enolate form, permitting relaxation to its neutral $\alpha$-hydroxyketone form.

For this explanation to be valid chromophore-protein interactions should favor the enolate form over the $\alpha$-hydroxyketone form. Thus, it would be of interest to investigate how specific short-range chromophore-protein interactions and long-range bulk electrostatic effects stabilize the various forms of astaxanthin inside the binding pocket of $\beta$-crustacyanin. While a detailed analysis of such interactions is beyond the scope of this work, it has previously been suggested, based on quantum chemical calculations, ${ }^{48}$ that the most proximal protein residues do not interact strongly with the neutral $\alpha$-hydroxyketone form, which at least does not go against the idea that the protein shifts the 
equilibrium between enolate and $\alpha$-hydroxyketone toward the former. Furthermore, this study also showed that the absorption of the $\alpha$-hydroxyketone form is rather insensitive to shortrange chromophore-protein interactions, which suggests that a more severe perturbation of the chromophore is needed to explain the bathochromic shift in the protein. Finally, preliminary B3LYP calculations that we have performed indicate that the histidine shifts the equilibrium between enolate and $\alpha$-hydroxyketone by at least $8 \mathrm{~kJ} \mathrm{~mol}^{-1}$ toward the former species.

Astaxanthin is not unique amongst carotenoids in its ability to form colored complexes with the crustacyanin protein, but the overwhelming majority of color-forming carotenoids (including actinioerythrol, violerythrin, iso-norastaxanthin, astacene, 19,19'dinorastacene, 4-hydroxy-4'-oxo- $\beta$ - $\beta$-carotene, adonirubin, 7,8didehydroastaxanthin and 15,15'-didehydroastaxanthin) possess structures with a fully conjugated polyene chain, ${ }^{2,49}$ linking oxygenated terminal rings with relatively acidic enolic or enolizable sites. Binding of carotenoids as an extended enolate within the protein may thus be a mechanism of some generality for formation of these spectacularly colored complexes in nature.

\section{Acknowledgements}

We thank Professor P. Zagalsky for invaluable comments and discussion. This work was supported by Bildungs- und Kulturdepartement des Kantons Luzern, Switzerland (A.H.), the Swedish Research Council (B.D.), the Olle Engkvist Foundation (B.D.), the Nuffield Foundation (S.B.), the School of Chemistry, University of Manchester (J.R.H., M.H., A.R., I.W.) and the European Molecular Biology Laboratory (M.C.).

\section{References}

1 I. Higuera-Ciapara, L. Félix-Valenzuela and F. M. Goycoolea, Crit. Rev. Food Sci. Nutr., 2006, 46, 185-196.

2 G. Britton, R. J. Weesie, D. Askin, J. D. Warburton, L. GallardoGuerrero, F. J. Jansen, H. J. M. de Groot, J. Lugtenburg, J.-P. Cornard and J.-C. Merlin, Pure Appl. Chem., 1997, 69, 2075-2084.

3 C. D. Dellisanti, S. Spinelli, C. Cambillau, J. B. C. Findlay, P. F. Zagalsky, S. Finet and V. Receveur-Brechot, FEBS Lett., 2003, 544, 189-193.

4 N. E. Chayen, M. Cianci, J. G. Grossmann, J. Habash, J. R. Helliwell, G. A. Nneji, J. Raftery, P. J. Rizkallah and P. F. Zagalsky, Acta Crystallogr., Sect. D: Biol. Crystallogr., 2003, 59, 2072-2082.

5 N. H. Rhys, M.-C. Wang, T. A. Jowitt, J. R. Helliwell, J. G. Grossmann and C. Baldock, J. Synchrotron Radiat., 2011, 18, 79-83.

6 M. Cianci, P. J. Rizkallah, A. Olczak, J. Raftery, N. E. Chayen, P. F. Zagalsky and J. R. Helliwell, Proc. Natl. Acad. Sci. U. S. A., 2002, 99, 9795-9800.

7 J. R. Helliwell, Crystallogr. Rev., 2010, 16, 231-242.
8 A. A. C. van Wijk, A. Spaans, N. Uzunbajakava, C. Otto, H. J. M. de Groot, J. Lugtenburg and F. Buda, J. Am. Chem. Soc., 2005, 127, 1438-1445.

9 A. Strambi and B. Durbeej, J. Phys. Chem. B, 2009, 113, 5311-5317.

10 N. Christensson, K. Žídek, N. C. M. Magdaong, A. M. LaFountain, H. A. Frank and D. Zigmantas, J. Phys. Chem. B, 2013, 117, 11209-11219.

11 R. Kuhn and N. A. Sörensen, Angew. Chem., 1938, 51, 465-466.

12 M. Buchwald and W. Jenks, Biochemistry, 1968, 7, 844-859.

13 Y. Abe, H. Horii, S. Taniguchi, K. Kamai and M. Takagi, Bull. Chem. Soc. Jpn., 1983, 56, 467-470.

14 M. M. T. Khan and A. E. Martell, J. Am. Chem. Soc., 1967, 89, 7104-7111.

15 V. R. Salares, N. M. Young, H. J. Bernstein and P. R. Carey, Biochim. Biophys. Acta, 1979, 576, 176-191.

16 C. Köpsel, H. Möltgen, H. Schuch, H. Auweter, K. Kleinermanns, H.-D. Martin and H. Bettermann, J. Mol. Struct., 2005, 750, 109-115.

17 R. Giovannetti, L. Alibabaei and F. Pucciarelli, Spectrochim. Acta, Part A, 2009, 73, 157-162.

18 E. Becher, R. Albrecht, K. Bernhard, H. G. W. Leuenberger, H. Mayer, R. K. Müller, W. Schüep and H. P. Wagner, Helv. Chim. Acta, 1981, 64, 2419-2435.

19 F. D. Negra, G. Santoni, M. Stivanello, M. Soukup and M. Fachini, PCT Int. Appl., WO2007072529, A2 20070628, 2007.

20 M. Cossi, N. Rega, G. Scalmani and V. Barone, J. Comput. Chem., 2003, 24, 669-681.

21 Y. Zhao and D. G. Truhlar, Theor. Chem. Acc., 2008, 120, 215-241.

22 O. Christiansen, H. Koch and P. Jørgensen, Chem. Phys. Lett., 1995, 243, 409-418.

23 C. Hättig, J. Chem. Phys., 2003, 118, 7751-7761.

24 M. A. L. Marques and E. K. U. Gross, Annu. Rev. Phys. Chem., 2004, 55, 427-455.

25 A. Dreuw and M. Head-Gordon, Chem. Rev., 2005, 105, 4009-4037.

26 M. E. Casida, J. Mal. Struct.: THEOCHEM, 2009, 914, 3-18.

27 Y. Zhao and D. G. Truhlar, J. Phys. Chem. A, 2006, 110, 13126-13130.

28 O. A. Vydrov and G. E. Scuseria, J. Chem. Phys., 2006, 125, 234109.

29 O. A. Vydrov, J. Heyd, A. V. Krukau and G. E. Scuseria, J. Chem. Phys., 2006, 125, 074106.

30 H. Iikura, T. Tsuneda, T. Yanai and K. Hirao, J. Chem. Phys., 2001, 115, 3540-3544.

31 K. Andersson, P.-Å. Malmqvist and B. O. Roos, J. Chem. Phys., 1992, 96, 1218-1226.

32 M. J. Frisch, G. W. Trucks, H. B. Schlegel, G. E. Scuseria, M. A. Robb, J. R. Cheeseman, G. Scalmani, V. Barone, B. Mennucci, G. A. Petersson, H. Nakatsuji, M. Caricato, X. Li, H. P. Hratchian, A. F. Izmaylov, J. Bloino, G. Zheng, J. L. Sonnenberg, M. Hada, M. Ehara, K. Toyota, R. Fukuda, J. Hasegawa, M. Ishida, T. Nakajima, Y. Honda, O. Kitao, 
H. Nakai, T. Vreven, J. A. Montgomery Jr, J. E. Peralta, F. Ogliaro, M. J. Bearpark, J. Heyd, E. N. Brothers, K. N. Kudin, V. N. Staroverov, R. Kobayashi, J. Normand, K. Raghavachari, A. P. Rendell, J. C. Burant, S. S. Iyengar, J. Tomasi, M. Cossi, N. Rega, N. J. Millam, M. Klene, J. E. Knox, J. B. Cross, V. Bakken, C. Adamo, J. Jaramillo, R. Gomperts, R. E. Stratmann, O. Yazyev, A. J. Austin, R. Cammi, C. Pomelli, J. W. Ochterski, R. L. Martin, K. Morokuma, V. G. Zakrzewski, G. A. Voth, P. Salvador, J. J. Dannenberg, S. Dapprich, A. D. Daniels, Ö. Farkas, J. B. Foresman, J. V. Ortiz, J. Cioslowski and D. J. Fox, Gaussian 09, Revision D.01, Gaussian, Inc., Wallingford, CT, USA, 2009.

33 TURBOMOLE V6.3 2011, a development of University of Karlsruhe and Forschungszentrum Karlsruhe $\mathrm{GmbH}$, 1989-2007, TURBOMOLE GmbH, since 2007; available at: http://www.turbomole.com, accessed July 25, 2013.

34 R. Ahlrichs, M. Bär, M. Häser, H. Horn and C. Kölmel, Chem. Phys. Lett., 1989, 162, 165-169.

35 F. Aquilante, L. D. Vico, N. Ferré, G. Ghigo, P.-Å. Malmqvist, P. Neogrády, T. B. Pedersen, M. Pitoňák, M. Reiher, B. O. Roos, L. Serrano-Andrés, M. Urban, V. Veryazov and R. Lindh, J. Comput. Chem., 2010, 31, 224-247.

36 A. T. Brünger, Nat. Protoc., 2007, 2, 2728-2733.

37 C. H. Arrowsmith, A. J. Kresge and Y. C. Tang, J. Am. Chem. Soc., 1991, 113, 179-182.
38 N. Kagayama, M. Sekiguchi, Y. Inada, H. D. Takagi and S. Funahashi, Inorg. Chem., 1994, 33, 1881-1885.

39 J. E. Crooks, Proton Transfer Reactions, Chapman and Hall, London, 1975.

40 S. Takahashi, L. A. Cohen, H. K. Miller and E. G. Peake, J. Org. Chem., 1971, 36, 1205-1209.

41 W. Adcock, J. Alste, S. Q. A. Rizvi and M. Aurangzeb, J. Am. Chem. Soc., 1976, 98, 1701-1711.

42 R. P. Bell and D. M. Goodall, Proc. R. Soc. London, Ser. A, 1966, 294, 273-297.

43 R. Brouillard and J.-E. Dubois, J. Org. Chem., 1974, 39, 1137-1142.

44 R. Kuhn and N. A. Sörensen, Ber. Dtsch. Chem. Ges. B, 1938, 71, 1879-1888.

45 J. R. Pliego Jr and J. M. Riveros, J. Phys. Chem. A, 2002, 106, 7434-7439.

46 G. Bartalucci, S. Fisher, J. R. Helliwell, M. Helliwell, S. LiaaenJensen, J. E. Warren and J. Wilkinson, Acta Crystallogr., Sect. B: Struct. Sci., 2009, 65, 238-247.

47 G. Bartalucci, J. Coppin, S. Fisher, G. Hall, J. R. Helliwell, M. Helliwell and S. Liaaen-Jensen, Acta Crystallogr., Sect. B: Struct. Sci., 2007, 63, 328-337.

48 J. Neugebauer, J. Veldstra and F. Buda, J. Phys. Chem. B, 2011, 115, 3216-3225.

49 W. L. Lee and P. F. Zagalsky, Biochem. J., 1966, 101, 9c-11c. 